\title{
Terapi Profilaksis versus On-Demand pada Pasien Hemofilia Berat dengan Hemartrosis
}

\author{
Ayi Dilla Septarini, Endang Windiastuti \\ Departemen Ilmu Kesehatan Anak, RS Dr Cipto Mangunkusumo, Fakultas Kedokteran Universitas \\ Indonesia, Jakarta
}

\begin{abstract}
Hemartrosis merupakan komplikasi perdarahan sendi yang paling sering terjadi pada pasien dengan hemofilia A, bila penanganan tidak adekuat maka kelainan sendi akan menjadi kronik dan menetap bahkan memburuk. Dilaporkan seorang anak lali-laki 14 tahun dengan diagnosis Hemofilia A sejak berusia 4 bulan. Keluhan nyeri dan bengkak sendi lutut dirasakan sejak tujuh tahun yang lalu. Pengobatan dengan pemberian faktor VIII konsentrat diberikan sesuai dengan kebutuhan, bila ada perdarahan (on-demand). Pada evaluasi foto radiologis menunjukkan gambaran artropati kronis lutut kanan. Artropati kronis seyogyanya dapat dicegah bila pemberian faktor VIII konsentrat secara rutin sebagai pencegahan hematrosis. Namun terdapat kesulitan karena keterbatasan penyediaan obat di Indonesia. (Sari Pediatri 2010;11(5):311-6).
\end{abstract}

Kata kunci: hemofilia, hemartrosis, terapi

$\mathrm{H}$ emofilia merupakan penyakit gangguan pembekuan darah herediter yang diturunkan secara $x$-linked recessive dengan frekuensi sekitar satu kasus dari 10.000 kelahiran. Hemofilia disebabkan oleh defisiensi faktor pembekuan VIII (hemofilia A) atau faktor IX (hemofilia B). Hemofilia A merupakan bentuk terbanyak dijumpai, sekitar $80 \%-85 \% .^{1,2}$ Klasifikasi hemofilia bergantung pada kadar faktor pembekuan dalam plasma, yaitu hemofilia berat apabila kadar kurang dari $1 \%$, sedang di antara $1 \%-5 \%$, dan ringan $5 \%-30 \% .^{1-3}$

\footnotetext{
Alamat korespondensi:

Dr. Endang Windiastuti, SpA(K). Divisi Hematologi Onkologi Departemen Ilmu Kesehatan Anak FKUI- RSCM Jl. Salemba no. 6, Jakarta 10430. Telepon: 021-3907744, 31901170 Fax.021-3913982
}

Anak dengan hemofilia berat memiliki risiko mengalami berbagai macam tipe perdarahan baik spontan maupun karena trauma, dengan jenis perdarahan tersering adalah hemartrosis (70\%-80\%). ${ }^{1}$ Hemartrosis sering berulang dan pada akhirnya dapat menyebabkan nyeri serta kelumpuhan (artropati). ${ }^{4}$ Pasien hemofilia berat dapat diobati dengan pemberian konsentrat faktor pembekuan 2-3 kali per minggu (profilaksis) untuk mencegah timbulnya perdarahan, atau hanya pada saat terjadi perdarahan (on-demand). ${ }^{4}$ Beberapa studi menunjukkan bahwa terapi profilaksis memberikan keuntungan dalam mencegah perdarahan dan kerusakan sendi. Kerugian terapi profilaksis adalah diperlukan konsentrat dalam jumlah besar dan biaya yang dibutuhkan meningkat. Oleh karena itu, pilihan regimen terapi yang digunakan harus disesuaikan dengan fasilitas kesehatan yang ada serta kondisi pasien dan keluarga. 
Ayi Dilla Septarini dkk: Terapi profilaksis vs on-demand hemofilia berat dengan hemartrosis

\section{Kasus}

Seorang anak lelaki berusia 14 tahun datang dengan keluhan utama lutut kiri bengkak hilang-timbul sejak tiga bulan yang lalu. Lutut juga terasa "ngilu" dan nyeri jika digerakkan serta pergerakan terbatas. Pasien berjalan menggunakan dua tongkat. Tidak ada riwayat trauma sebelumnya dan tidak ada perdarahan lain. Di rumah, pasien melakukan prinsip RICE (rest, ice, compression, elevation). Sejak tujuh tahun yang lalu, pasien sering mengalami bengkak di lutut hilang-timbul, pasien tidak berobat ke dokter, tidak ditransfusi, lutut hanya diistirahatkan, dan bengkak sembuh dengan sendirinya. Sejak dua bulan yang lalu, jika lutut bengkak, pasien berobat rutin ke Poliklinik Hematologi Departemen Ilmu Kesehatan Anak RSCM, untuk kemudian mendapatkan transfusi konsentrat faktor VIII $20 \mathrm{IU} / \mathrm{kg}$ (1000 IU) setiap duapuluh empat jam selama dua hari berturut-turut. Setelah mendapatkan transfusi, bengkak di lutut dan nyeri berkurang, namun pasien masih berjalan menggunakan dua tongkat untuk mengurangi beban tubuh. Pasien didiagnosis menderita hemofilia sejak usia 4 bulan, namun belum pernah diperiksa kadar faktor VIII dan faktor IX karena ketiadaan biaya.

Pasien adalah anak kedua dari tiga bersaudara, berasal dari keluarga golongan sosial ekonomi menengah. Selama berobat pasien mendapatkan pengobatan konsentrat faktor VIII dengan menggunakan kartu Asuransi Kesehatan (Askes). Kakak laki-laki pasien juga menderita hemofilia, meninggal pada usia 2 tahun karena perdarahan intrakranial. Riwayat kehamilan, persalinan, dan tumbuh kembang normal, saat ini pasien duduk di sekolah menengah pertama kelas 3 . Imunisasi dasar lengkap, asupan nutrisi kesan cukup.

Pada pemeriksaan fisis didapatkan berat badan $48 \mathrm{~kg}$ dan tinggi badan $169 \mathrm{~cm}$ (gizi kurang). Tanda vital dan status generalis pediatrik dalam batas normal. Pada status lokalis, di regio genu sinistra didapatkan hemartrosis, nyeri tekan, fleksi sendi genu sinistra terbatas (range of motion $90^{\circ}$ ). Pemeriksaan laboratorium yang dilakukan satu bulan yang lalu menunjukkan kadar faktor VIII <1\% (40\%-140\%), sedangkan kadar faktor IX 52\% (51\%-137\%). Pada pemeriksaan radiologis genu sinistra didapatkan gambaran hemartrosis kronik.

Pasien didiagnosis hemofilia A berat dengan hemartrosis genu sinistra, mendapatkan terapi transfusi konsentrat faktor VIII 20 IU/kg setiap duapuluh empat jam selama dua hari berturut-turut.

\section{Pertanyaan klinis}

Mengingat belum diterapkan terapi profilaksis faktor VIII pada hemofilia dengan hemartrosis di Indonesia, maka diformulasikan pertanyaan klinis sebagai berikut, "Pada anak hemofilia berat dengan hemartrosis, apakah terapi profilaksis lebih baik dalam mencegah kerusakan sendi dibandingkan dengan terapi on-demand?"

\section{Metode/strategi penelusuran bukti}

Prosedur pencarian literatur untuk menjawab masalah klinis telah ditelusuri pustaka secara online dengan mempergunakan instrumen pencari Pubmed, Google, Yahoo, dan Cochrane Library dengan memakai kata kunci "hemophilia", "hemarthrosis", "prophylaxis", dan "on-demand". Penelusuran lebih lanjut secara manual pada daftar pustaka yang relevan. Levels of evidence ditentukan berdasarkan klasifikasi Oxford Centre for Evidence-based Medicine Levels of Evidence. ${ }^{5}$

\section{Hasil penelusuran}

Melalui metode pencarian literatur, pada awalnya didapatkan 105 artikel yang memenuhi kriteria. Dalam penelusuran abstrak artikel, didapatkan 16 artikel yang relevan dengan masalah, yaitu satu artikel meta-analisis, dua artikel uji klinis acak terkontrol, enam artikel review, dan tujuh artikel kohort.

Data yang menunjang kelebihan terapi profilaksis pada hemofilia sebagian besar merupakan studi retrospektif yang rentan terhadap confounding by indication, yakni perancu yang terjadi akibat indikasi pemberian terapi profilaksis ditentukan oleh dokter yang merawat. Studi tersebut tersebut mengevaluasi dampak perbedaan regimen terapi pada frekuensi perdarahan terutama perdarahan sendi, dan outcome klinis jangka panjang terhadap terjadinya artropati. Penilitian menilai klinis dan skor radiologis, sedangkan pada beberapa kasus, dinilai kualitas hidup pasien dengan melaporkan jumlah kunjungan dan perawatan di rumah sakit, dan absensi di sekolah/tempat kerja. ${ }^{6-10}$

Pada pasien dengan hemofilia berat, terapi profilaksis telah digunakan lebih dari empatpuluh tahun di Eropa Utara, dewasa ini di negara-negara 
Eropa lainnya dan Amerika Utara. Terapi profilaksis merupakan pilihan pertama yang direkomendasikan oleh World Health Organisation (WHO) dan World Federation of Haemophilia (WFH) sejak 1994 (level of evidence: 2b). ${ }^{6}$ Tujuan terapi profilaksis untuk mencegah perdarahan berat atau yang mengancam nyawa, serta mencegah artropati sehingga pasien dapat hidup normal tanpa proteksi yang berlebihan. ${ }^{7}$ Pasien yang diberi terapi profilaksis dilaporkan memiliki perbedaan kualitas hidup yang bermakna dibandingkan terapi on-demand yaitu kondisi umum yang lebih baik, nyeri berkurang, dan skor yang lebih tinggi pada fungsi psikis, kesehatan mental, dan fungsi sosial (level of evidence: 2b). ${ }^{8}$

Kreuz dkk ${ }^{9}$ melaporkan bahwa tidak ada artropati yang terdeteksi pada anak yang telah mendapatkan terapi profilaksis sebelum usia dua tahun dan tidak lebih dari satu perdarahan sendi (level of evidence: $2 b$ ). Van den Berg $\mathrm{dkk}^{10}$ melaporkan bahwa jika terapi profilaksis dimulai pada usia empat tahun maka terjadi penurunan bermakna frekuensi perdarahan sendi, namun tidak mencegah timbulnya artropati pada sebagian besar pasien (level of evidence: $2 b$ ).

Mengingat penyakit hemofilia relatif dijumpai dan kesulitan untuk melakukan uji klinis acak terkontrol menyebabkan Cochrane reviewers pada tahun $2005^{3}$ mengidentifikasi hanya empat uji klinis menyilang (cross-over trials) berskala kecil (tiga studi dilakukan pada tahun 1970-an, satu studi dilakukan pada tahun 1997), membandingkan terapi profilaksis dengan plasebo atau dua regimen profilaksis yang berbeda. Heterogenitas desain studi, intervensi dan karakteristik pasien menghambat meta-analisis, sehingga hanya melibatkan 44 pasien. Pada tahun 2005, belum ada uji klinis acak terkontrol yang membandingkan terapi profilaksis dengan on-demand. Sebagai kesimpulan, Cochrane reviewers menyimpulkan bahwa tidak ada bukti yang cukup untuk mendukung kelebihan klinis dari terapi profilaksis dibandingkan on-demand, oleh karena itu diperlukan uji klinis acak terkontrol untuk menjawab masalah ini (level of evidence: 1a).

Kesimpulan tersebut menggarisbawahi ketidakpastian implementasi terapi profilaksis pada anak, yang memerlukan evidence yang sahih untuk dapat diterapkan dalam sistem kesehatan. Namun, banyak kritik disampaikan terhadap penekanan yang terlalu kaku pada uji klinis acak terkontrol, sehingga dapat menghalangi perkembangan terapi, yakni terapi profilaksis yang aman dan efektif yang terbukti dengan desain penelitian lainnya. ${ }^{11,12}$ Uji klinis acak terkontrol sulit dilakukan pada penyakit kronik seperti hemofilia, dengan perspektif seumur hidup, yang bertujuan untuk mengetahui efektifitas terapi jangka panjang, dengan memperhatikan rasio cost-effectiveness (outcome sendi, kecacatan, biaya kesehatan untuk perawatan di rumah sakit, fisioterapi, prosedur ortopedi dan kualitas hidup pasien). ${ }^{11}$ Kesimpulan Cochrane Reviewers tampaknya terlalu dini karena saat ini telah dilaporkan dua uji klinis acak terkontrol (RCT randomized controlled trial) yang membandingkan terapi profilaksis dan on-demand.

Uji klinis acak terkontrol pertama mengenai terapi profilaksis versus on-demand dipublikasi pada bulan Agustus 2007 oleh Manco-Johnson dkk. ${ }^{4}$ Studi tersebut memiliki outcome primer yang menekankan pada pencegahan kerusakan sendi dengan terapi profilaksis yang dimulai sebelum atau saat terjadinya perdarahan sendi yang kedua (antara usia 6-30 bulan). Dari studi Manco-Johnson dkk didapatkan enam kali penurunan risiko kerusakan sendi pada anak dengan terapi profilaksis (25 IU/kg selang sehari) dibandingkan dengan anak yang mendapatkan terapi on-demand, penilaian dilakukan melalui gambaran radiologis dan atau magnetic resonance imaging (MRI) sendi pada usia enam tahun (level of evidence: 1b). Outcome yang didapatkan pada studi Manco-Johnson $\mathrm{dkk}^{4}$ dilaporkan pada Tabel 1 .

Dari studi Manco-Johnson dkk dilaporkan terdapat perbedaan bermakna pada pemeriksaan MRI sendi yang, dari separuh abnormalitas sendi tidak terdeteksi dengan pemeriksaan radiologis standar. Pemeriksaan MRI lebih baik digunakan pada anak hemofilia untuk mendeteksi kerusakan sendi daripada pemeriksaan radiologis, walaupun tanpa riwayat hemartrosis atau abnormalitas pada pemeriksaan fisis. ${ }^{4}$ Tabel 2 membandingkan studi Manco-Johnson dkk dengan uji klinis acak terkontrol lainnya yang dilakukan di Italia (studi Gringeri $\mathrm{A}^{13}$ ). Hasil akhir dari studi Gringeri A akan segera dipublikasikan dengan menyajikan data outcome jangka panjang (sepuluh tahun) pada anak yang menerima terapi profilaksis.

\section{Pembahasan}

Pasien hemofilia pada kasus kami mengalami hemartrosis genu sinistra yang merupakan jenis perdarahan tersering pada hemofilia $(70 \%-80 \%)$, dan predileksi tersering adalah sendi lutut $(45 \%) .{ }^{1}$ 
Tabel 1. Hasil studi Manco-Johnson $\mathrm{dkk}^{4}$

\begin{tabular}{lccc}
\hline Parameter outcome & Profilaksis & On-demand & $p$ \\
\hline Jumlah pasien yang mengikuti penelitian & 32 & 33 & \\
Jumlah pasien yang dievaluasi (primary end-point)* & 28 & 29 & \\
& & & \\
Data outcome & & & \\
- Perdarahan sendi (n per tahun, median) & 0.2 & 4.35 & $<0.001$ \\
- Total perdarahan (n per tahun, median) & 1.15 & 17.1 & $<0.001$ \\
- Jumlah konsentat faktor VIII (IU per tahun, rata-rata) & 325,793 & 113,237 & $<0.001$ \\
- Tidak ada kerusakan sendi pada Röntgen (n, \%) & $27 / 28(96)$ & $22 / 27(81)$ & 0.1 \\
- Tidak ada kerusakan sendi pada MRI (n, \%) & $25 / 27(93)$ & $16 / 29(55)$ & 0.002 \\
& & & \\
Efek samping berat & & & 0.24 \\
- Inhibitor titer tinggi (n) & 2 & 0 & 0.24 \\
- Perdarahan masif (n) & 0 & 3 & 0.9 \\
- Dirawat di rumah sakit (n per tahun, median)\# & 0.25 & 0.24 & 0.2 \\
- Akses vena sentral (n \%) & $29(91)$ & $25(76)$ & 0.95 \\
- Infeksi akibat akses vena sentral (n) & 6 & 6 & \\
\hline
\end{tabular}

Keterangan: MRI: magnetic reconance imaging; ${ }^{*}$ Data radiologis dan/atau MRI pada akhir studi, pada usia 6 tahun; \# Dirawat dengan indikasi yang berhubungan dengan hemofilia.

Tabel 2. Perbandingan studi Manco-Johnson $\mathrm{dkk}^{4}$ dan studi Gringeri $\mathrm{A}^{13}$

\begin{tabular}{lcc}
\hline & Manco-Johnson dkk & Gringeri A\# \\
\hline Desain & Uji klinis acak terkontrol & Uji klinis acak terkontrol \\
Waktu penelitian & $08 / 1996-04 / 2005$ & $12 / 1996-2008$ \\
Jumlah pasien & 65 & 45 \\
n (profilaksis/on-demand) & $(32 / 33)$ & $(23 / 22)$ \\
Jumlah pasien yang dievaluasi* & 57 & 40 \\
n (profilaksis/on-demand) & $(28 / 29)$ & $(20 / 20)$ \\
Usia rata-rata, (tahun) & 1.6 & 4.0 \\
Follow-up, (bulan) & 49 & 120 \\
& & \\
Kriteria inklusi & $<30$ & $<84$ \\
Usia (bulan) & $<2$ & $\geq 1$ \\
Kadar faktor VIII (\%) & $\leq 2$ & \\
Perdarahan sendi & & \\
& & \\
Intervensi & & \\
Terapi profilaksis, faktor VIII & 25 IU/kg, selang sehari & (target faktor VIII $>1 \%)$ \\
Terapi on-demand, faktor VIII & kg pada 24 dan 72 jam sesudahnya, & sembuh \\
& serta selang sehari sampai sembuh & \\
\hline
\end{tabular}

*Keterangan studi Manco-Johnson dkk, jumlah pasien dengan data radiologis pada akhir penelitian. Studi Gringeri A, jumlah pasien yang mengikuti jenis terapi sesuai randomisasi; ${ }^{* *}$ minimal satu perdarahan sendi atau otot pada 6 bulan sebelum randomisasi; \#Hasil studi belum dipublikasi 
Selama dua bulan terakhir pasien mendapatkan terapi on-demand, yaitu pengobatan diberikan jika terjadi hemartrosis berulang. Pengobatan konsentrat faktor VIII $20 \mathrm{IU} / \mathrm{kg}$ (1000 IU) yang diberikan selama dua hari berturut-turut. Dosis diberikan sesuai dengan protokol terapi di Indonesia maupun di negara lain. ${ }^{14-17}$ Namun idealnya, pasien mendapatkan transfusi 1000 IU konsentrat faktor VIII setiap 12 jam, sampai gejala hilang. Pengobatan tidak memungkinkan pada pasien karena dengan ditanggung oleh Askes, pasien hanya mendapatkan8vial (@250 IU) dalam 1 minggu sehingga hanya bisa diberikan 2x1000 IU dalam 1 minggu.

Menurut protokol WFH untuk negara berkembang, jika terdapat perdarahan sendi diberikan konsentrat faktor pembekuan selama 1-2 hari atau lebih jika respons tidak adekuat. Sedangkan untuk negara maju jika terdapat perdarahan berulang pada sendi, pasien diberikan konsentrat faktor pembekuan sebagai profilaksis jangka pendek selama 4-8 minggu untuk menghentikan siklus perdarahan, dan dikombinasikan dengan fisioterapi. Disarankan pemberian profilaksis konsentrat faktor pembekuan sebelum beraktivitas yang berisiko tinggi. Saat ini, protokol yang dianjurkan untuk terapi profilaksis adalah transfusi konsentrat faktor pembekuan 25-40 IU/kg, tiga kali seminggu pada pasien hemofilia A dan dua kali seminggu pada pasien hemofilia B. ${ }^{1}$ Protokol terapi profilaksis sampai saat ini belum dapat diterapkan di Indonesia, penghambat utama adalah masalah biaya yang diperlukan untuk pemberian konsentrat faktor VIII.

\section{Kesimpulan}

Bukti mutakhir studi uji klinis acak terkontrol (meskipun jumlahnya terbatas) menegaskan keunggulan pemberian terapi profilaksis konsentrat faktor pembekuan pada hemofilia, yang sudah lama dianjurkan berdasarkan studi dengan level of evidence yang lebih rendah. Terapi profilaksis telah terbukti menurunkan frekuensi dan derajat perdarahan sendi, sehingga dapat memelihara fungsi sendi dan mempertahankan kualitas hidup.

Masalah ketersediaan konsentrat faktor pembekuan dan biaya yang diperlukan merupakan penghambat utama penerapan terapi profilaksis di negara berkembang, termasuk Indonesia. Namun perlu ditegaskan bahwa terapi profilaksis dalam jangka panjang sangat cost-effective, karena dapat mengurangi biaya tinggi yang diperlukan jika terjadi kerusakan sendi. Studi cost-efficacy diperlukan untuk mengidentifikasi dosis minimum konsentrat faktor pembekuan yang diperlukan untuk menurunkan biaya terapi dan memungkinkan penerapan terapi profilaksis di negara berkembang. Perubahan kebijakan Askes untuk menambah 'jatah' pemberian konsentrat faktor pembekuan, program-program Pemerintah lainnya untuk pasien yang tidak mampu, serta lembaga swadaya masyarakat yang peduli terhadap pasien hemofilia kiranya dapat mempercepat penerapan terapi profilaksis pada setiap pasien yang memerlukannya, sehingga dapat memperbaiki kualitas hidup pasien.

\section{Daftar Pustaka}

1. World Federation of Hemophilia. Guidelines for the management of hemophilia. Montreal: World Federation of Hemophilia, 2005.

2. Bell B, Canty D, Audet M. Hemophilia: An updated review. Pediatr Rev 1995;16:290-8.

3. Stobart K, Iorio A, Wu JK. Clotting factor concentrates given to prevent bleeding and bleeding related complications in people with hemophilia A or B. Cochrane Database of Syst Rev. 2006;2:CD003429.

4. Manco-Johnson MJ, Abshire TC, Shapiro AD, Riske B, Hacker MR, Kilcoyne R, dkk. Prophylaxis versus episodic treatment to prevent joint disease in boys with severe hemophilia. N Engl J Med 2007;6:535-44.

5. Oxford Centre of Evidence-based Medicine. Oxford Centre for Evidence-based Medicine Levels of Evidence (March 2009). Diunduh dari: http://www.cebm.net/index. asox?o=1025. Diakses tanggal 9 Juni 2009.

6. Nillson IM, Berntorp E, Löfqvist T, Pettersson H. Twenty-five years experience of prophylactic treatment in severe haemophilia A and B. J Intern Med 1992;232:2532.

7. Ljung R. Prevention of bleeding in haemophilia: Trends, overcoming barriers and future treatment options. Haemophilia 2007;13 (Suppl 2):1-3.

8. Royal S, Schramm W, Berntorp E, Giangrande P, Gringeri A, Ludlam C, dkk. Quality-of-life differences between prophylactic and on-demand factor replacement therapy in European haemophilia patients. Haemophilia 2002;8:44-50.

9. Kreuz W, Escuriola-Ettingshausen C, Funk M, Schmidt 
H, Kornhuber B. When should prophylactic treatment in patients with haemophilia A and B start? The German experience. Haemophilia 1998;4:413-7.

10. Van den Berg HM, Fischer K, Mauser-Bunschoten EP, Beek FJA, Roosendaal G, van der Bom JG. Longterm outcome of individualized prophylactic treatment of children with severe haemophilia. Br J Haematol 2001;112:561-5.

11. Fischer K, Grobbee DE, van den Berg HM. RCTs and observational studies to determine the effect of prophylaxis in severe haemophilia. Haemophilia 2007; 13:245-50.

12. Manucci PM. Need for randomized trials in haemophilia. J Thromb Haemost 2006;4:501-2.

13. Gringeri A. Prospective controlled study on prophylaxis:
An Italian approach. Haemophilia 2003;9(Suppl 1):3843.

14. Indonesian Hemophilia Society. The golden standard theraphy for hemophilia A (Factor VIII). Diunduh dari http://www.hemofilia.or.id/koate.php. Diakses tanggal 11 Juni 2009.

15. Srivastava A, You SK, Ayob Y, Chuansumrit A, de Bosch N, Bianco RP, dkk. Hemophilia treatment in developing countries: Products and protocols. Semin Thromb Hemost 2005;31:495-500.

16. Gilham A. Guideline for the Treatment of Haemophilia in South Africa. SAMJ 2007;97:1296-311.

17. Petrini P. What factors should influence the dosage and interval of prophylactic treatment in patients with severe hemophilia A and B? Haemophilia 2001;7:99-102. 